\title{
Influence of Water-Cement Ratio and Type of Mixing Water on the Early Hydration Performance of Calcium Sulphoaluminate (CSA) Cement
}

\author{
Chuanlin Wang ${ }^{1,2,3}$ and Meimei Song ${ }^{4}$ \\ ${ }^{1}$ Department of Civil and Environmental Engineering, Shantou University, Shantou 515063, China \\ ${ }^{2}$ Key Laboratory of Structure and Wind Tunnel of Guangdong Higher Education Institutes, Shantou 515063, China \\ ${ }^{3}$ Guangdong Engineering Center for Structure Safety and Health Monitoring, Shantou University, Shantou 515063, China \\ ${ }^{4}$ Department of Mechanical Engineering, Xi'an Shiyou University, Xi'an 710065, China
}

Correspondence should be addressed to Meimei Song; mmsong@xsyu.edu.cn

Received 6 January 2021; Revised 12 April 2021; Accepted 5 May 2021; Published 20 May 2021

Academic Editor: Robert Černý

Copyright (c) 2021 Chuanlin Wang and Meimei Song. This is an open access article distributed under the Creative Commons Attribution License, which permits unrestricted use, distribution, and reproduction in any medium, provided the original work is properly cited.

\begin{abstract}
The present work studies the influence of water-cement ratio and types of mixing water on the hydration process and microstructure of calcium sulphoaluminate (CSA) cement. Experimental tests on the setting time, physical properties, compressive strength, chemical shrinkage, X-ray diffraction (XRD), and scanning electron microscopy (SEM) of CSA cement paste were carried out. The XRD analysis confirmed that the main hydration product is ettringite in both freshwater and seawater mixed CSA cement with different w/c ratios. The SEM analysis and physical properties test show that both low w/c ratio and seawater can improve the microstructure of CSA cement. The test results also find out that the high $\mathrm{w} / \mathrm{c}$ ratio can accelerate the hydration process, extend the setting time, lower the compressive strength, and increase the chemical shrinkage of CSA cement, and the seawater presents a similar influence except for the mechanical property. The seawater increases the compressive strength of CSA cement in the early stage of hydration but will increase the microcracks at the later hydration stage of CSA cement and reduce its mechanical properties.
\end{abstract}

\section{Introduction}

Calcium sulphoaluminate (CSA) cement is considered an environmentally friendly material, which has been used in China for more than 40 years $[1,2]$. It has become increasingly popular in civil engineering nowadays because of its rapid hydration speed, high early strength [3], high impermeability $[4,5]$ and sulfate corrosion resistance $[4,6]$, lower energy consumption $[7,8]$, and lower $\mathrm{CO}_{2}$ emissions during the calcination process of cement clinkers [6], as well as its low drying shrinkage and low solution alkalinity [9]. Ettringite and aluminum gel are the main hydration products of CSA cement produced via the chemical reaction shown in equation (1), which has good corrosion resistance against sulfate attack [10], where the absence of calcium hydroxide is another advantage for CSA in sulfate environment.
The primary mechanism of sulfate attack is the chemical interaction between sulfate ions and hydration products [11]. Therefore, the usual approaches to create sulfateresisting concrete are improving the permeability to stop the permeation of sulfate ions and controlling the chemical composition of cement to decrease the unfavorable raw materials [10]. When there is calcium hydroxide in the hydration products of Portland cement, $\mathrm{Ca}(\mathrm{OH})_{2}$ will react with the sulfate ions in seawater to create gypsum, which is shown in equation (2). When the gypsum is depleted, the AFt will transform to AFm, which is shown in equation (3). However, if the sulfate ions keep penetrating into the concrete matrix, the AFm will react with sulfate ions to produce AFt again, which is shown in equation (4). Equations (2) to (4) show that the seawater may provide sulfate attack against Portland cement. 


$$
\begin{gathered}
3 \mathrm{CaO} \cdot 3 \mathrm{Al}_{2} \mathrm{O}_{3} \cdot \mathrm{CaSO}_{4}+34 \mathrm{H}_{2} \mathrm{O} \longrightarrow 3 \mathrm{CaO} \cdot \mathrm{Al}_{2} \mathrm{O}_{3} \cdot 3 \mathrm{CaSO}_{4} \cdot 32 \mathrm{H}_{2} \mathrm{O}(\mathrm{AFt})+2\left(\mathrm{Al}_{2} \mathrm{O}_{3} \cdot 3 \mathrm{H}_{2} \mathrm{O}\right) \\
\mathrm{Ca}(\mathrm{OH})_{2}+\mathrm{Na}_{2} \mathrm{SO}_{4}+2 \mathrm{H}_{2} \mathrm{O} \longrightarrow \mathrm{CaSO}_{4} \cdot 2 \mathrm{H}_{2} \mathrm{O}+2 \mathrm{NaOH} \\
\mathrm{AFt}+2\left(3 \mathrm{CaO} \cdot \mathrm{Al}_{2} \mathrm{O}_{3} \cdot 6 \mathrm{H}_{2} \mathrm{O}\right) \longrightarrow 3\left(3 \mathrm{CaO} \cdot \mathrm{Al}_{2} \mathrm{O}_{3} \cdot \mathrm{CaSO}_{4} \cdot 12 \mathrm{H}_{2} \mathrm{O}\right)(\mathrm{AFm}) \\
2\left(\mathrm{CaSO}_{4} \cdot 2 \mathrm{H}_{2} \mathrm{O}\right)+\mathrm{AFm}+16 \mathrm{H}_{2} \mathrm{O} \longrightarrow \mathrm{AFt}
\end{gathered}
$$

CSA cement is a potential material that can be used in the marine environment as explained in equation (1). Xu et al. [12] pointed out that CSA cement can significantly improve the microstructure of concrete and decrease the water absorption rate compared with OPC. Some other researches [4, 13-15] have also concluded that the CSA cement can reduce the porosity of concrete.

Usually, decreasing $\mathrm{w} / \mathrm{c}$ ratio is a very effective approach to improve the sulfate resistance of concrete. $\mathrm{w} / \mathrm{c}$ ratio is one of the most fundamental parameters in concrete mixture proportioning [16] as excessive water causes strength reduction, while insufficient water incurs poor workability [17]. Hou et al. [10] found that the CSA cement with a w/c ratio of 0.5 had a much greater diffusion coefficient of sulfate ions than the CSA with a w/c ratio of 0.3. Wang et al. [18] also concluded that a lower $\mathrm{w} / \mathrm{c}$ provides a more obvious increase in the strength. Luo et al. [19] explained that the capillary pores were interconnected in the cement matrix with a high w/c ratio, which helps to transfer external ions into the inside of the matrix. Zhou and Ge [20] found that the mortar with a low w/c ratio is more brittle than that of mortar with a high w/c ratio. Zivica [21] also studied the influence of the $\mathrm{w} / \mathrm{c}$ ratio on the mechanical performance and microstructure of the cement paste.

Many researches have proved that seawater can be applied in the production of concrete [22, 23]. Wang et al. [24] found that the concrete mixed with sweater develops more enriched hydrates and finer microstructure. Seawater contains a large number of ions (mainly chloride and sulfate ions), where it has been already recognized that it can influence the properties of concrete [13]. However, there exists a debate on the influence of seawater on the properties of concrete [25-28]. Kaushik et al. [29] reported that the compressive strength of concrete mixed with seawater was cut down compared with the concrete mixed with freshwater. But Xiao et al. [30] and Shi et al. [31] reported that seawater can improve concrete's mechanical properties. At present, most of the researches were conducted on concrete made of Portland cement $[32,33]$ or on the CSA mixed with freshwater $[34,35]$, and there is a lack of studies on the concrete made of CSA cement mixed with seawater. It is known from equation (1) that the chemical reaction immediately occurs when CSA clinkers meet with calcium sulfate and water, and there exist lots of free $\mathrm{SO}_{4}^{2-}$ in seawater. Therefore, it can be assured that the seawater definitely affects the properties of CSA cement. In summary, it is necessary to investigate the influence of the $\mathrm{w} / \mathrm{c}$ ratio and mixing water on the hydration of CSA cement to promote a wider application of CSA cement in offshore engineering.
This paper aims to analyze the effects of mixing water with different w/c ratios on the hydration process of CSA cement. The influence is evaluated by conducting tests on the setting time, physical properties, compressive strength, and chemical shrinkage of sulphoaluminate cement. Furthermore, the microstructure and hydration products of CSA cement are analyzed via X-ray diffraction (XRD) and scanning electron microscopy (SEM) as well.

\section{Materials and Test Methods}

2.1. Raw Materials. Commercial fast hardening CSA cement 42.5 is adopted in this research. Its main compositions and properties are shown in Tables 1 and 2, and its XRD patterns are shown in Figure 1. Seawater is prepared manually by dissolving sea salt into freshwater, whose main chemical compositions are shown in Table 3. Freshwater is tap water.

2.2. Sample Preparation. The $\mathrm{w} / \mathrm{c}$ ratios of $0.48,0.44,0.40$, 0.36 , and 0.32 were considered for investigation. The specimens were demoulded after $12 \mathrm{~h}$ and then cured in a steaming environment at $20^{\circ} \mathrm{C}$ for $1 \mathrm{~d}, 3 \mathrm{~d}$, and $7 \mathrm{~d}$.

2.3. Test Method. The method to determine the setting time of CSA paste is adjusted based on the Chinese code "Test methods for water requirement of normal consistency, setting time and soundness of the Portland cement" (GB/T 1346-2011) [36]. The compressive strength of CSA paste was tested on a $50 \mathrm{~mm} \times 50 \mathrm{~mm} \times 50 \mathrm{~mm}$ specimen. The specimens were compressed with a loading speed of $2.4 \mathrm{kN} / \mathrm{s}$. The test rig to determine the chemical shrinkage of CSA paste was carried out based on American Standard ASTM C160812 [37], which is illustrated in Figure 2. The physical properties of CSA paste were recorded according to the American Standard ASTM C20-2015 [38]. The measurement of XRD on CSA paste was performed using a diffractometer provided by Bruker at $40 \mathrm{kV}$ and $40 \mathrm{~mA}$ between $10^{\circ}$ and $60^{\circ}$ $(2 \theta)$ at a step size of 0.0333 degrees. The SEM investigation on CSA paste was performed on JEOL JSM 6360LA.

\section{Experimental Results and Discussion}

3.1. Influence on the Setting Time. Figure 3 shows the influence of the w/c ratio and mixing water on the initial and final setting time of CSA cement. It can be seen that the w/c ratio and the mixing water have an evident impact on the hydration process of CSA cement. The initial setting time and final setting time of CSA were greatly delayed with the 
TABLE 1: Chemical compositions of CSA (\%).

\begin{tabular}{lcccccc}
\hline $\mathrm{MgO}$ & $\mathrm{SiO}_{2}$ & $\mathrm{Al}_{2} \mathrm{O}_{3}$ & $\mathrm{SO}_{3}$ & $\mathrm{CaO}$ & $\mathrm{Fe}_{2} \mathrm{O}_{3}$ & $\mathrm{TiO}_{2}$ \\
\hline 1.85 & 6.71 & 25.52 & 12.02 & 45.96 & 4.35 & 1.36 \\
\hline
\end{tabular}

Table 2: Properties of CSA.

\begin{tabular}{lcccccc}
\hline \multirow{2}{*}{ Fineness gravity, $\mathrm{m}^{2} / \mathrm{kg}$} & \multicolumn{2}{c}{ Setting time $(\mathrm{min})$} & \multicolumn{2}{c}{$\begin{array}{c}\text { Strength in } 1 \mathrm{~d}(\mathrm{MPa}) \\
\text { Compressive }\end{array}$} & \multicolumn{2}{c}{$\begin{array}{c}\text { Strength in } 3 \mathrm{~d}(\mathrm{MPa}) \\
\text { Flexural }\end{array}$} \\
& Initial & Final & Flexural & 35.8 & 6.6 & Compressive \\
\hline 408 & 15 & 30 & 6.3 & 45.8 \\
\hline
\end{tabular}

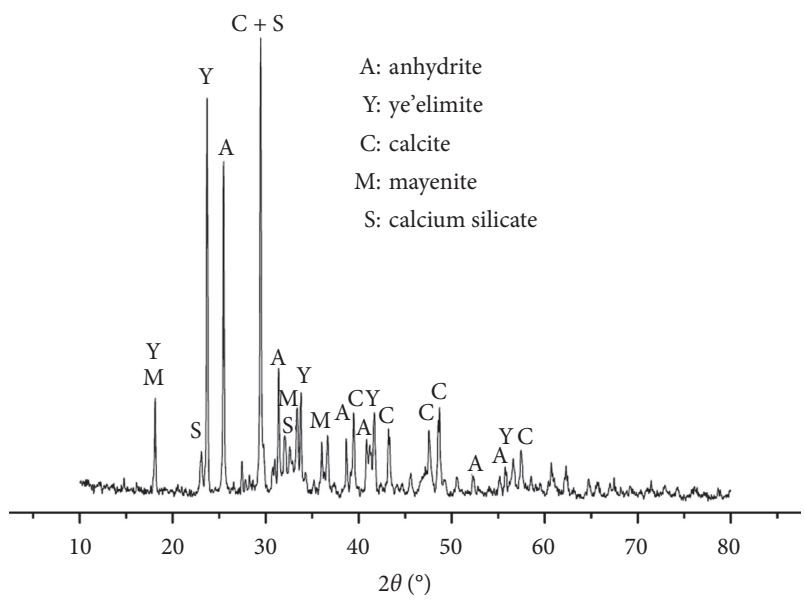

Figure 1: XRD patterns of CSA.

TABle 3: Composition of artificial seawater (g/L).

\begin{tabular}{lcccc}
\hline $\mathrm{NaCl}$ & $\mathrm{MgCl}_{2}$ & $\mathrm{Na}_{2} \mathrm{SO}_{4}$ & $\mathrm{CaCl}_{2}$ & $\mathrm{KCl}$ \\
\hline 24.36 & 5.12 & 4.02 & 1.16 & 0.69 \\
\hline
\end{tabular}

increase of the $\mathrm{w} / \mathrm{c}$ ratio. When the $\mathrm{w} / \mathrm{c}$ ratio was increased from 0.32 to 0.48 , the initial setting time of CSA cement mixed with freshwater and seawater was delayed by $7 \mathrm{~min}$ and $9 \mathrm{~min}$, respectively, and the final setting time was delayed by $10 \mathrm{~min}$ and $11 \mathrm{~min}$, respectively. Besides, the initial and final setting time of CSA cement mixed with seawater was longer than that of freshwater mixed under any $\mathrm{w} / \mathrm{c}$ ratio, which indicates that seawater can delay the initial and final setting time of CSA cement. This conclusion can also be verified from Figure 4(a) in Section 3.5. Though, in the researches in $[25,28,39]$ on Portland cement, the seawater can reduce the setting time, in the research in [40] on the fast hardening cement, like potassium magnesium phosphate cement, seawater can postpone the initial setting time. Also, Huang et al. [41] found that seawater can slightly retard the setting time of magnesium oxychloride cement.

The setting and hardening time of cement paste are mainly determined by the speed and quantity of hydration products of the cement slurry. The hydration products will form a network structure after setting, which will change the cement slurry and reduce the plasticity of the paste, and the paste then starts to harden gradually. When the $\mathrm{w} / \mathrm{c}$ ratio is small, the distance between cement particles is small, which is easy to form the skeleton of the structure, resulting in a

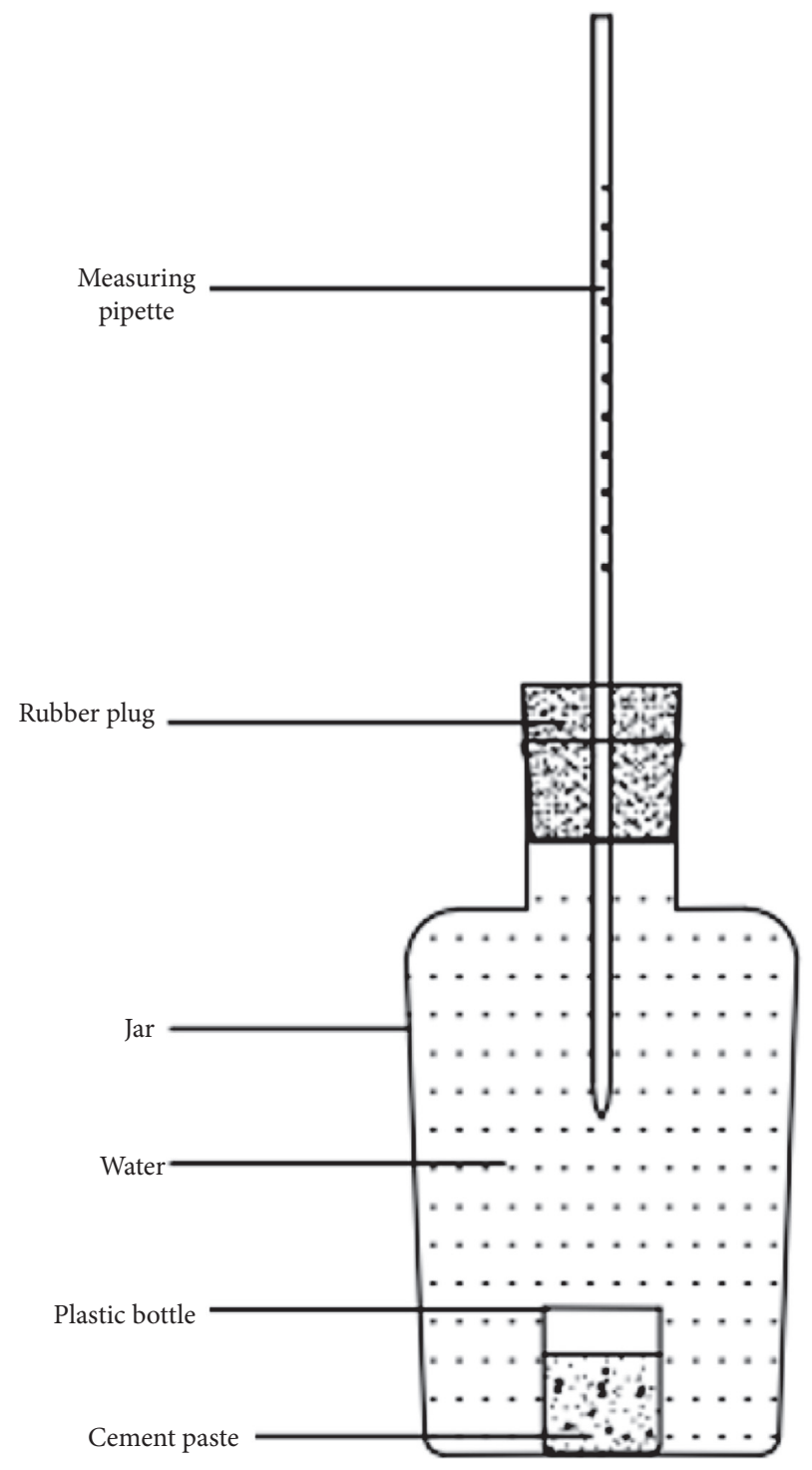

Figure 2: Chemical shrinkage device.

shorter setting time. The larger the $\mathrm{w} / \mathrm{c}$ ratio, the more structural pores are needed to be filled by hydration products during the setting of cement paste, which leads to the extension of setting and hardening time.

The reason why the seawater can delay the initial setting and final setting time of CSA cement is the $\mathrm{SO}_{4}^{2-}$ in seawater that plays a significant role. There are a lot of free sulfate ions 


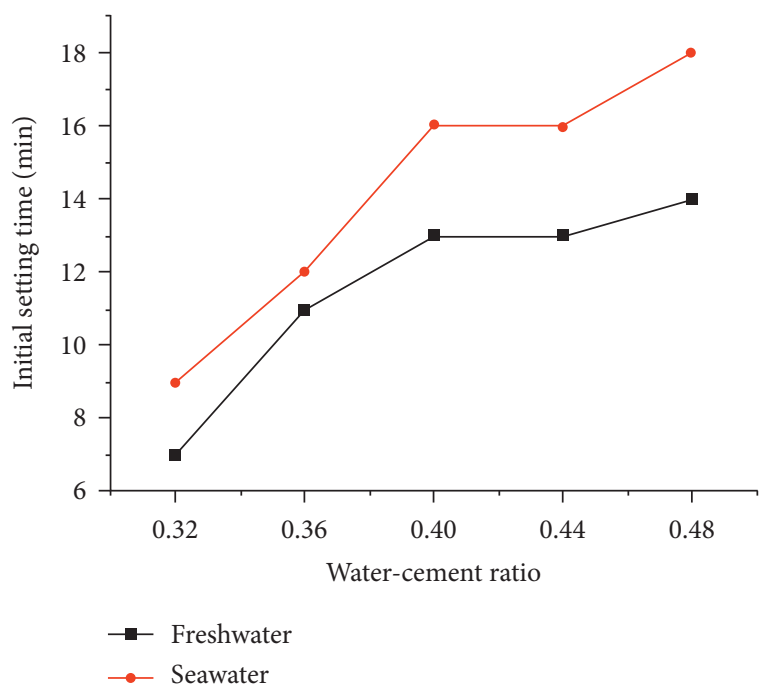

(a)

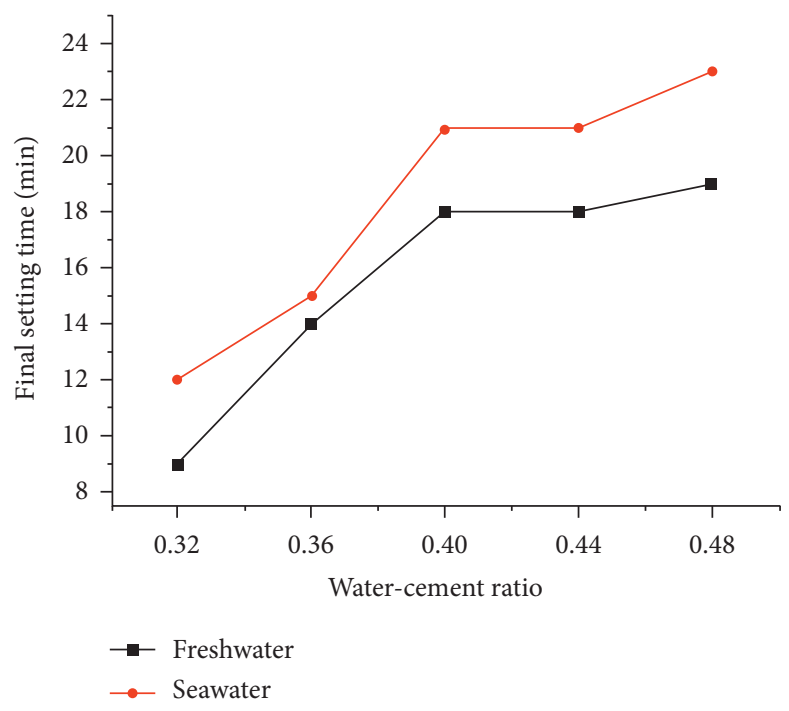

(b)

FIgURE 3: Influence curves of w/c ratio and mixing water on the setting time of CSA cement. (a) Initial setting time. (b) Final setting time.

in seawater, which can rapidly combine with calcium ions in CSA cement to form gypsum, and gypsum can combine with $\mathrm{C}_{4} \mathrm{~A}_{3} \mathrm{~S}$ to form insoluble ettringite, which precipitates and adheres on the surface of cement particles and hinders the further hydration of CSA cement.

3.2. Influence on the Physical Properties. The influence of the $\mathrm{w} / \mathrm{c}$ ratio and mixing water on the physical properties of CSA cement paste is listed in Table 4. It displays that the $\mathrm{w} / \mathrm{c}$ ratio has a remarkable influence on the physical properties of CSA paste. Specifically, the lower the w/c ratio, the lower the porosity and the water absorption, which leads to greater compactness. The excessive water in cement paste with a higher $\mathrm{w} / \mathrm{c}$ ratio will evaporate and leave more pores in the matrix. Furthermore, the seawater as mixing water can slightly reduce the porosity and improve the compactness of CSA paste. The reason is that the ions in seawater react with the clinkers in CSA and produce hydration products to fill the pores. Moreover, the salts in the seawater which do not participate in the hydration will also fill the pores.

3.3. Influence on the Compressive Strength. Figure 5 displays the strength curves of CSA cement mixed with freshwater and seawater with different $\mathrm{w} / \mathrm{c}$ ratios. It can be seen that CSA cement has the characteristics of super early strength and high strength under any type of mixing water. After curing for $1 \mathrm{~d}$, the compressive strength of CSA paste ranges from $40 \mathrm{MPa}$ to $62 \mathrm{MPa}$. For CSA mixed with freshwater, the compressive strength increases slightly with the increase of curing time. For the seawater mixed CSA cement, when the curing time was increased from $1 \mathrm{~d}$ to $3 \mathrm{~d}$, the compressive strength is greatly improved. However, when the curing time was increased to $7 \mathrm{~d}$, the compressive strength of all specimens did not change much or even decreased slightly except for the group with a w/c ratio of 0.48 .
It also shows that the w/c ratio has a very significant effect on the compressive strength of CSA cement. Specifically, the performance is presented as follows: the lower the $\mathrm{w} / \mathrm{c}$ ratio, the higher the compressive strength of CSA paste mixed with both seawater and freshwater. Besides, compared with freshwater mixing, seawater mixing can improve the compressive strength of CSA paste at the early stage of curing, and the higher the $\mathrm{w} / \mathrm{c}$ ratio, the more obvious the improvement. However, when the curing time reaches $7 \mathrm{~d}$, the effect of seawater on the compressive strength of CSA paste differs at different $\mathrm{w} / \mathrm{c}$ ratios. The results show that the compressive strength of CSA cement is still promoted by seawater at higher w/c ratios ( 0.48 and 0.44$)$, but at lower w/c ratios $(0.40,0.36$, and 0.32$)$, the compressive strength of CSA paste mixed with seawater is slightly lower than that mixed with freshwater.

The above experimental phenomenon is mainly due to the existence of a large amount of free $\mathrm{SO}_{4}^{2-}$ in seawater, which can fasten the hydration of CSA cement to form ettringite in the early stage. The reaction process is shown in equation (1). Ettringite is one of the main products of CSA cement hydration, which can promote the strength formation of CSA cement. Therefore, compared with freshwater mixed, the compressive strength of CSA paste mixed with seawater increases faster because the hydration degree and the amount of ettringite produced in seawater mixed CSA paste are greater in the early stage. In the later stage of hydration, a large quantity of ettringite is produced, and the internal space of CSA cement matrix is filled up; the excess ettringite will squeeze the matrix and increase the expansion ratio of CSA cement matrix. Due to the low tensile strength of CSA, microcracks appear in the expansion process of the matrix, which leads to the decrease of matrix strength in the later stage. For the CSA cement mixed with a high w/c ratio, the large amount of free water in the matrix will form more pores during evaporation in the hydration process, and the 


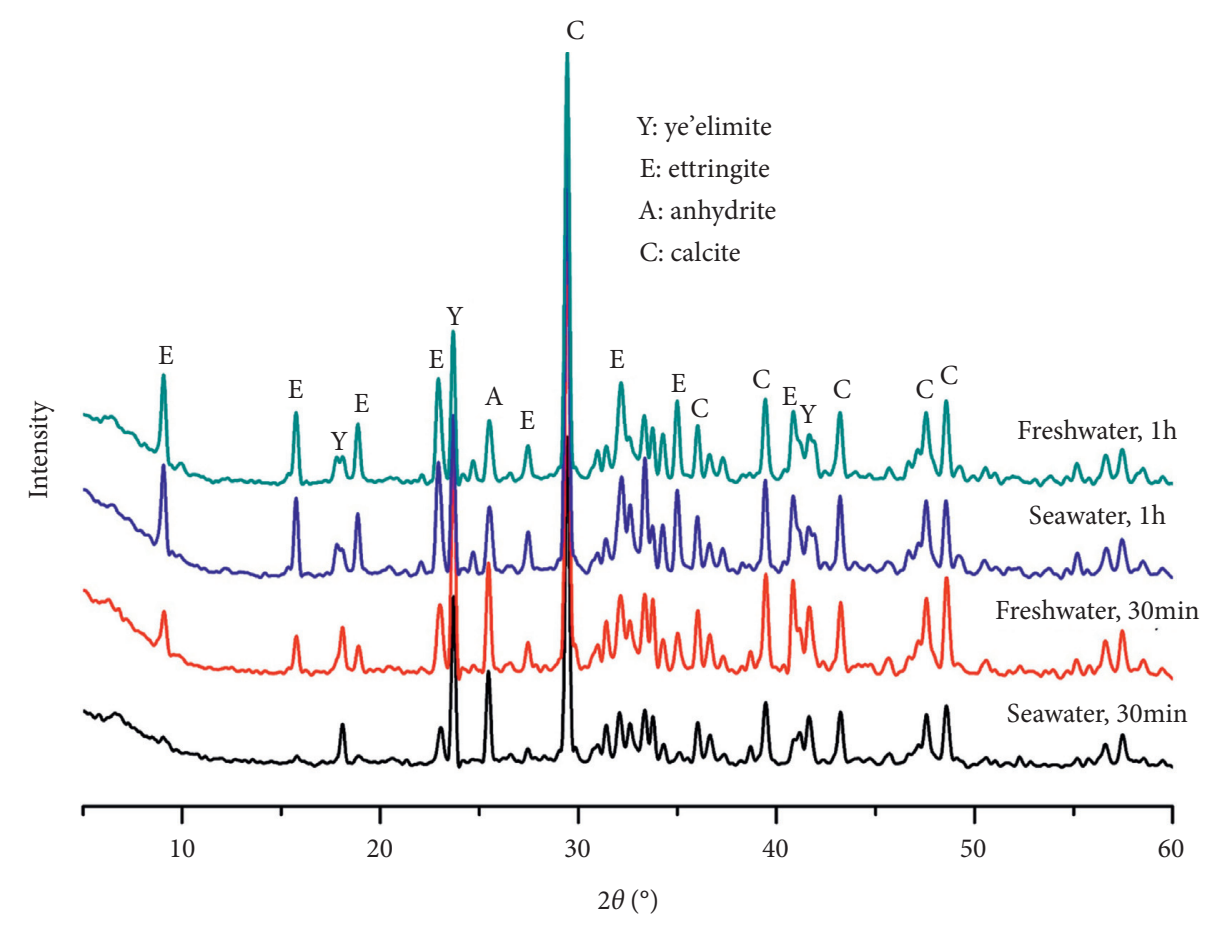

(a)

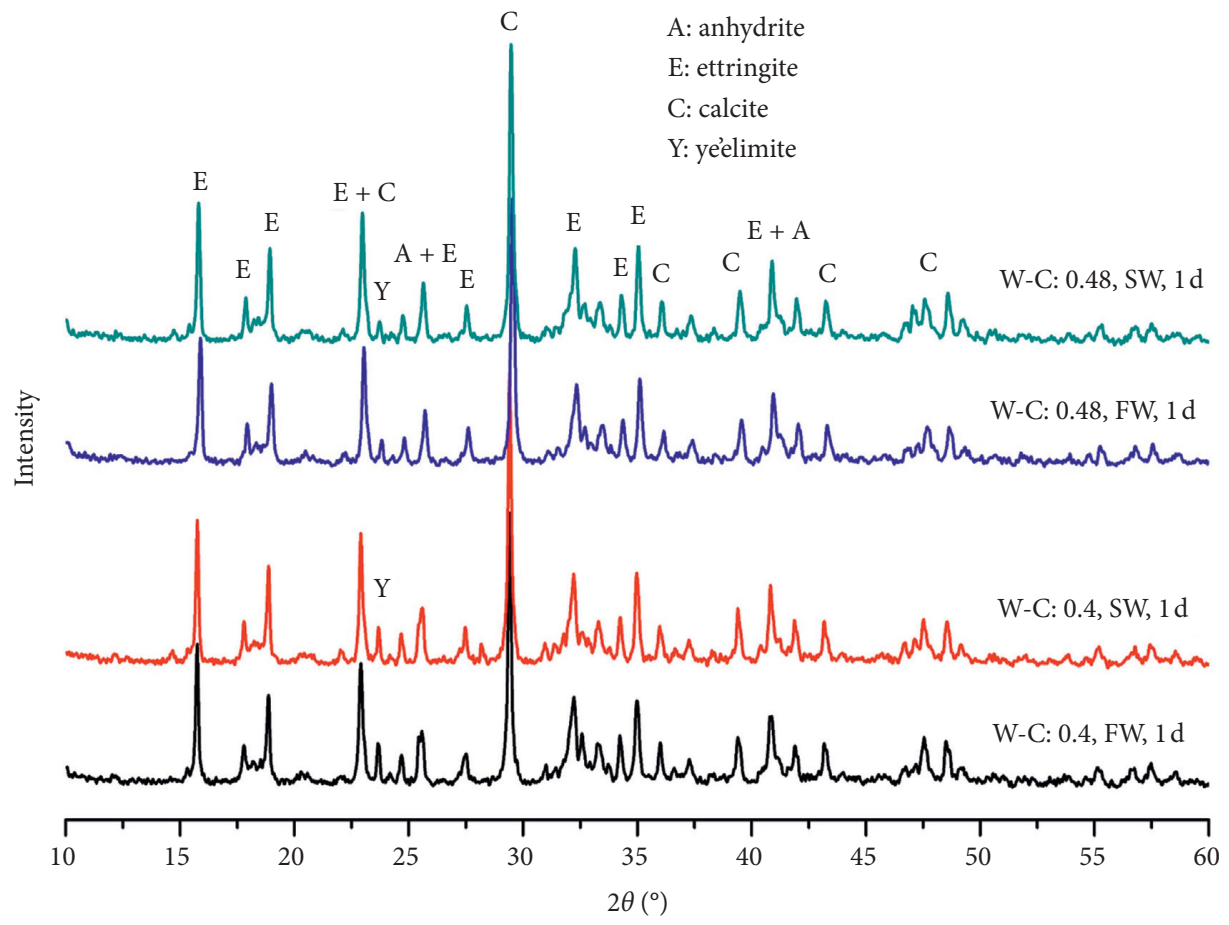

(b)

Figure 4: Continued. 


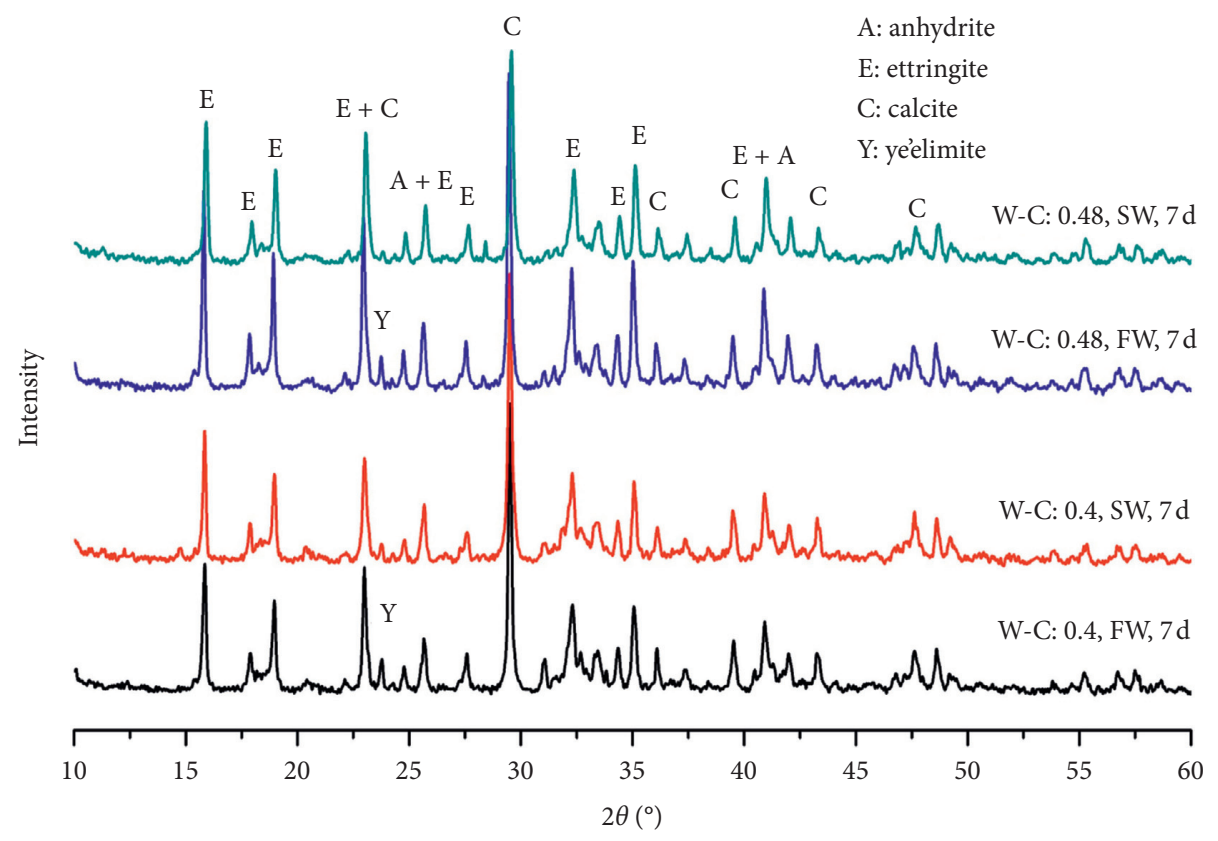

(c)

FIGURE 4: XRD patterns of CSA cement with different types of mixing water and w/c ratios. (a) CSA cement paste with different mixing water cured for $30 \mathrm{~min}$ and $1 \mathrm{~h}$. (b) CSA pastes cured for $1 \mathrm{~d}$. (c) CSA pastes cured for $7 \mathrm{~d}$.

produced ettringite will fill the pores in the formation process. Therefore, the strength of CSA cement mixed with a high w/c ratio (0.48) will increase to a certain extent even after curing for $7 \mathrm{~d}$.

3.4. Influence on the Chemical Shrinkage. Figure 6 shows the influence curves of the $\mathrm{w} / \mathrm{c}$ ratio and mixing water on the chemical shrinkage of CSA cement. The shrinkage is caused when CSA reacts with water and anhydrite, and the volume of hydration product is smaller than the volume sum of materials before reaction. It can be seen from the figure that the $\mathrm{w} / \mathrm{c}$ ratio has a significant effect on the chemical shrinkage of CSA cement, while the type of mixing water does not have a noticeable effect on the chemical shrinkage of CSA cement compared with the w/c ratio. Specifically, the lower the w/c ratio, the lower the chemical shrinkage of CSA paste. The reason for the higher $\mathrm{w} / \mathrm{c}$ ratio resulting in higher chemical shrinkage is that the higher $\mathrm{w} / \mathrm{c}$ ratio provides more water, which can speed up the hydration process. When the hydration of cement particles is completed, the chemical shrinkage tends to be stable.

The chemical shrinkage value of CSA cement mixed with seawater is very close to that of freshwater mixed at a higher $\mathrm{w} / \mathrm{c}$ ratio (0.48 and 0.40$)$. However, at a lower $\mathrm{w} / \mathrm{c}$ ratio (0.32), the chemical shrinkage of CSA mixed with freshwater is slightly greater than that of CSA mixed with seawater. The $\mathrm{SO}_{4}^{2-}$ in seawater combines with the ye'elimite in the CSA cement clinkers to form insoluble ettringite. As the combination speed is very fast, this causes the early produced ettringite to precipitate and adhere to the surface of cement particles and hinders the further hydration of CSA cement, which means that the seawater delays the hydration process in the very early stage, which is in accordance with the findings in the setting time as well as in Figure 4(a). However, when the CSA particles were depleted, the chemical shrinkage of CSA pastes mixed with different w/c ratios will gradually approach in the later stage of hydration.

3.5. XRD Analysis. Figure 4 shows the effect of mixing water and $w / c$ ratio on the hydration products of CSA cement. It can be seen from the figure that the hydration speed of CSA cement is very fast under different w/c ratios. Figure 4(a) illustrates that seawater can delay the setting time of CSA cement. After curing for $30 \mathrm{~min}$, the XRD peak of ettringite of CSA paste mixed with freshwater is much higher and stronger than the paste mixed with seawater, which agrees with the findings on setting time. The reason can be found in Section 3.1. However, after curing for $1 \mathrm{~h}$, there is no much difference between freshwater and seawater. Combining with Figure 4(b), the XRD peak of ettringite of CSA paste mixed with seawater is stronger than that of the one mixed with freshwater. The above phenomena show that the seawater can delay the setting time of CSA cement in the very early hydration stage. However, the sweater will accelerate the hydration process after curing for $1 \mathrm{~h}$.

Figure 4(b) illustrates that there is still a small amount of unhydrated CSA particles after curing for $1 \mathrm{~d}$ for the CSA cement mixed with both freshwater and seawater with a w/c ratio of 0.40 . It can also be found that there is a small amount of unhydrated cement particles in the CSA cement mixed with a $0.48 \mathrm{w} / \mathrm{c}$ ratio. However, compared with the sample with a w/c ratio of 0.40 , the diffraction peak decreases significantly, which indicates that increasing the water binder ratio can promote the hydration of CSA cement. 
TABLE 4: The physical properties of CSA paste with different w/c ratios and mixing water.

\begin{tabular}{lccccc}
\hline $\begin{array}{l}\text { Water-cement } \\
\text { ratio }\end{array}$ & Type of mixing water & Porosity (\%) & Water absorption (\%) & $\begin{array}{c}\text { Apparent specific gravity } \\
\left(\mathrm{g} \cdot \mathrm{cm}^{-3}\right)\end{array}$ & $\begin{array}{c}\text { Bulk density } \\
\left(\mathrm{g} \cdot \mathrm{cm}^{-3}\right)\end{array}$ \\
\hline \multirow{2}{*}{0.40} & Freshwater & 0.3997 & 0.2563 & 2.5984 & 1.5597 \\
& Seawater & 0.4013 & 0.2570 & 2.6085 & 1.5616 \\
0.48 & Freshwater & 0.4683 & 0.3311 & 2.6612 & 1.4148 \\
& Seawater & 0.4532 & 0.3196 & 2.5941 & 1.4184 \\
\hline
\end{tabular}

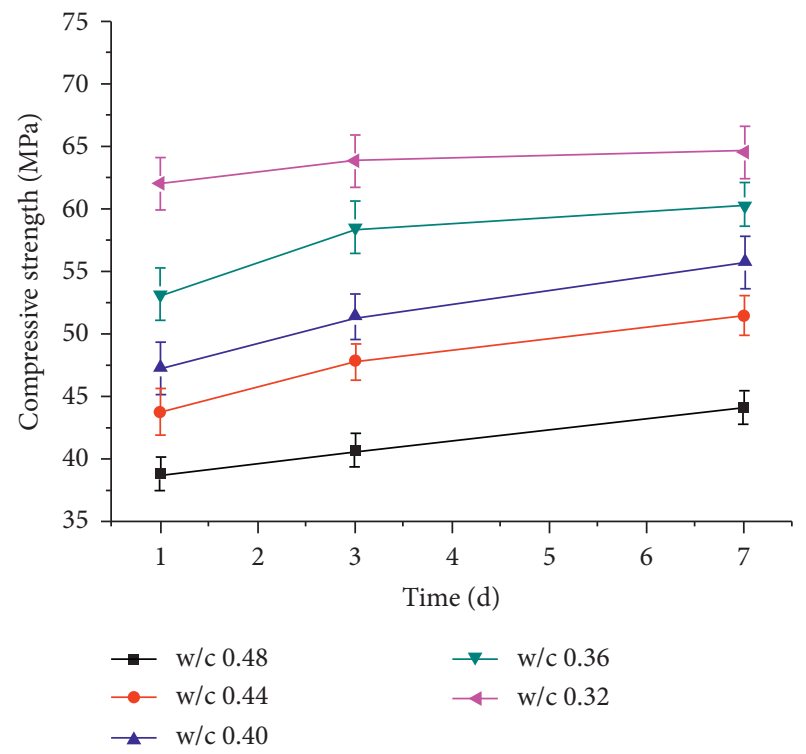

(a)

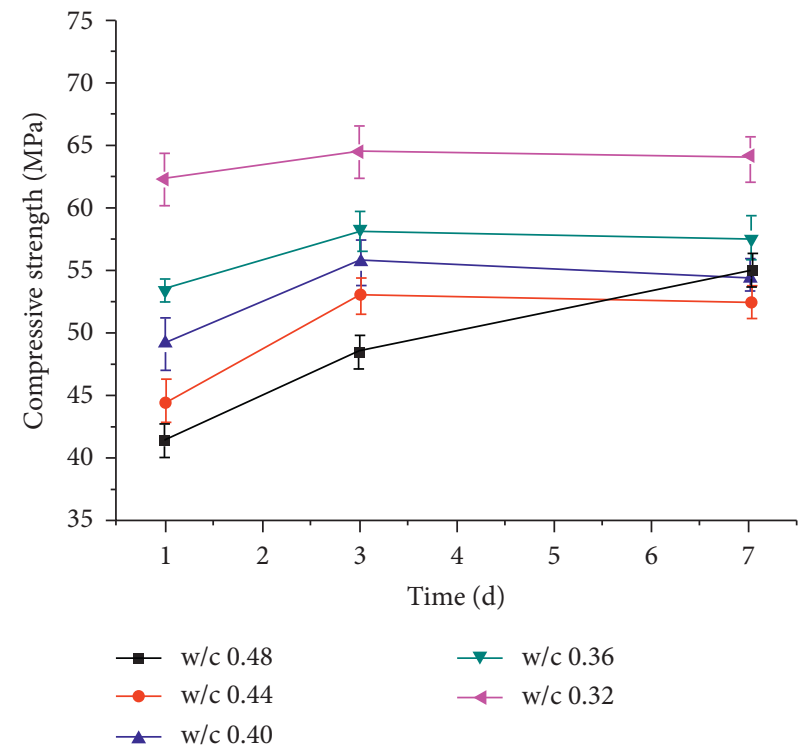

(b)

Figure 5: The influence of w/c ratio on the compressive strength of CSA cement. (a) Freshwater. (b) Seawater.

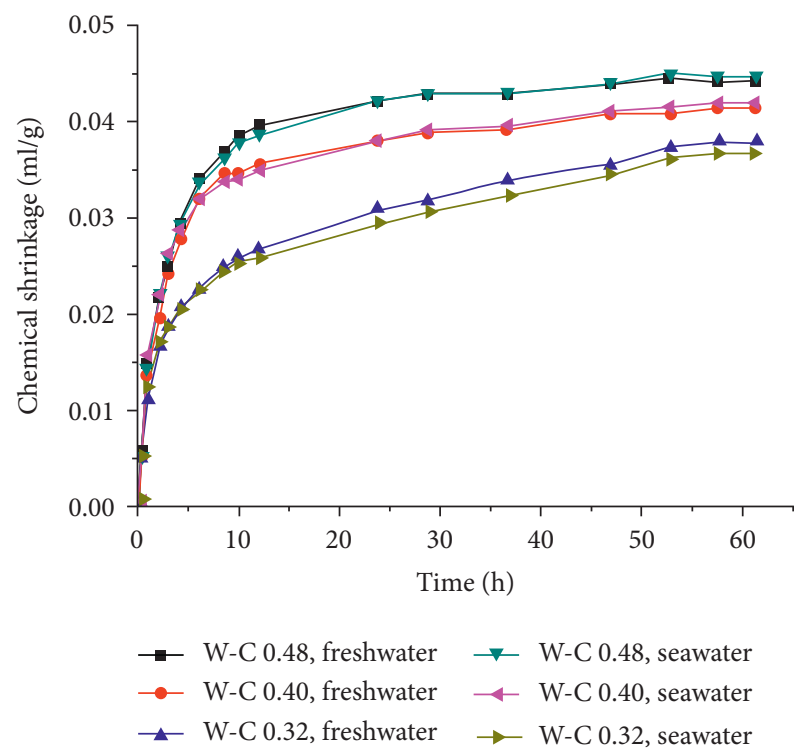

FIGURE 6: Influence of w/c ratio and mixing water on chemical shrinkage of CSA paste.

However, it should be noted that the hydration degree does not ensure a better mechanical performance as the mechanical property is also related to the microstructure of the paste.

Figure 4(c) shows the XRD analysis results of CSA cement after curing for $7 \mathrm{~d}$. When the $\mathrm{w} / \mathrm{c}$ ratio is 0.40 , there are still some unhydrated cement particles in the freshwater mixed samples, which indicates that the hydration is continuing. However, the diffraction peak of CSA crystals can hardly be seen in the sample mixed with seawater, indicating that the hydration of CSA is almost complete. Furthermore, the samples with a w/c ratio of 0.48 present similar results, indicating that seawater and a high $\mathrm{w} / \mathrm{c}$ ratio can promote the hydration of CSA. This is because the hydration of CSA requires the participation of water and calcium sulfate (see equation (1)), while seawater and high w/c ratio can provide more free sulfate ions and water; therefore, the hydration degree of CSA cement mixed with seawater and greater w/c ratio is increased.

3.6. SEM Analysis. Figure 7 shows the SEM diagrams of CSA cement mixed with seawater and freshwater at different w/c ratios. From the comparative analysis of Figures $7(\mathrm{a})$ and $7(b)$, it can be seen that the ettringite production of CSA paste mixed with seawater after $1 \mathrm{~d}$ hydration is more at the $\mathrm{w} / \mathrm{c}$ ratio of 0.40 , and the matrix density is also higher. This is mainly because sulfate ions in seawater promote the hydration of CSA cement and produce more ettringite. 


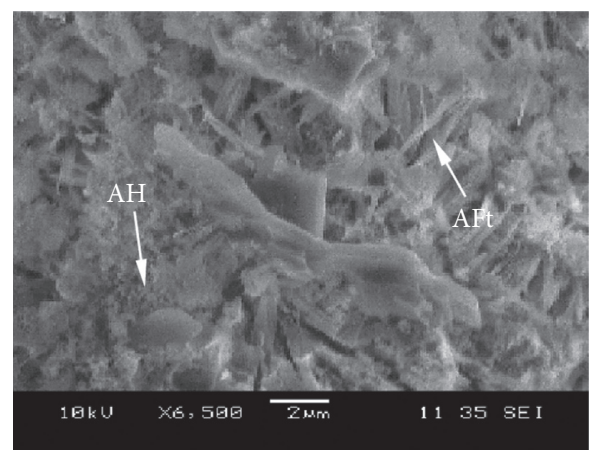

(a)

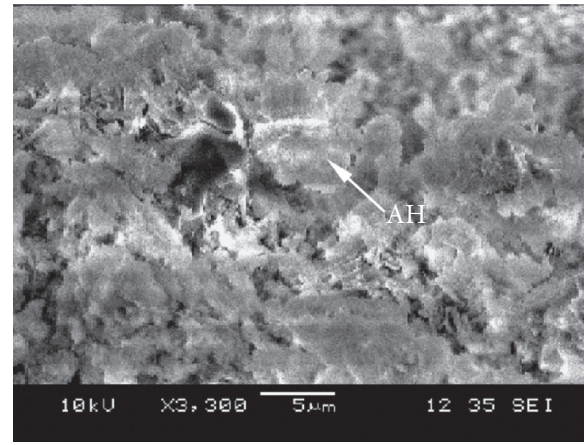

(c)

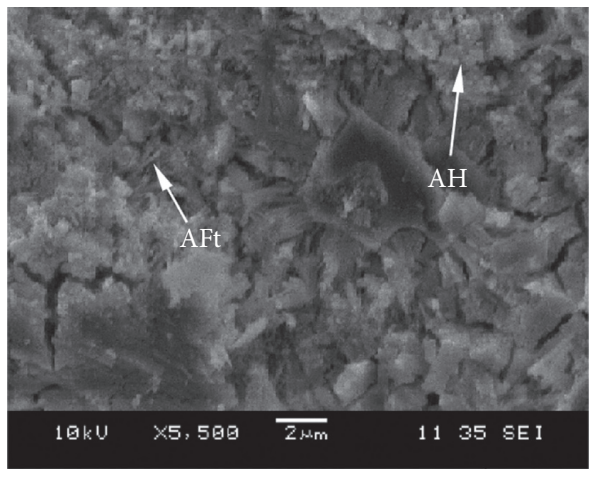

(e)

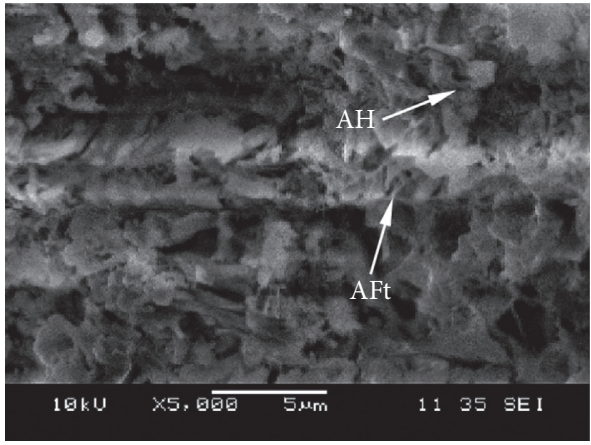

(g)

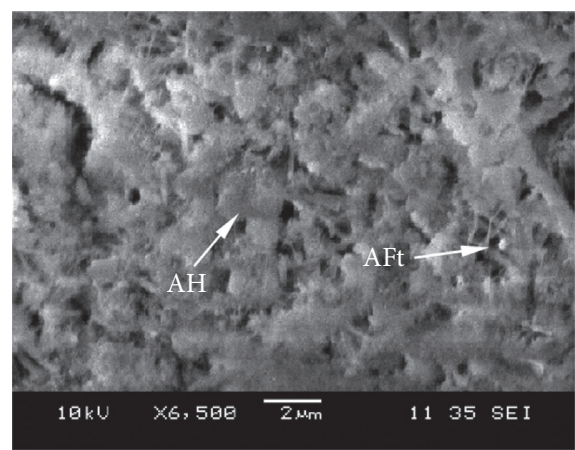

(b)

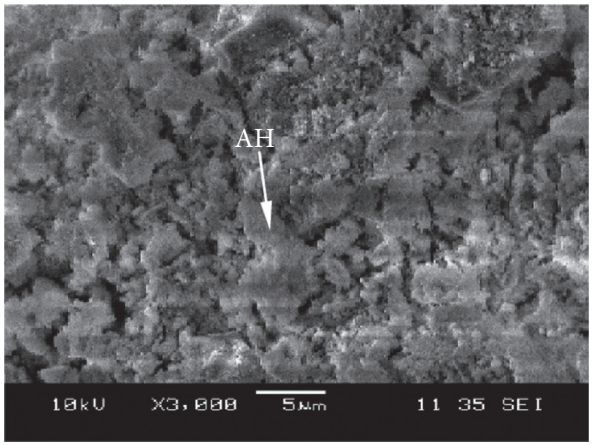

(d)

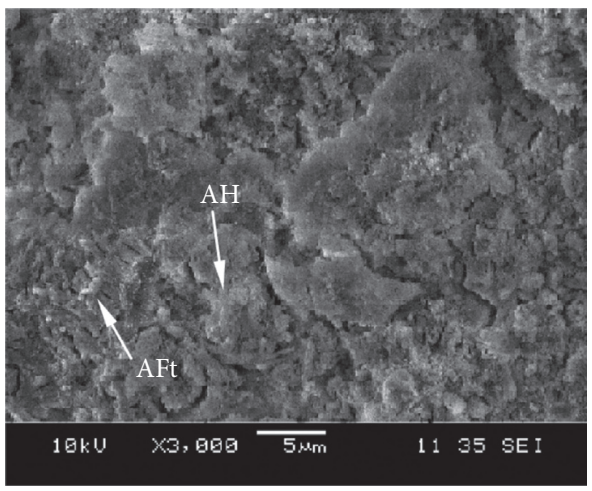

(f)

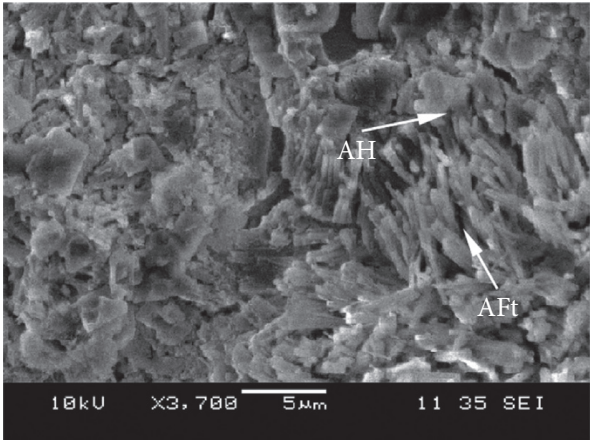

(h)

FiguRE 7: SEM diagrams of CSA cement mixed with different mixing water and w/c ratios. (a) Freshwater with w/c of 0.40 cured for $1 \mathrm{~d}$. (b) Seawater with w/c of 0.40 cured for $1 \mathrm{~d}$. (c) Freshwater with w/c of 0.48 cured for $1 \mathrm{~d}$. (d) Seawater with w/c of 0.48 cured for $1 \mathrm{~d}$. (e) Freshwater with w/c of 0.40 cured for $7 \mathrm{~d}$. (f) Seawater with w/c of 0.40 cured for $7 \mathrm{~d}$. (g) Freshwater with w/c of 0.48 cured for $7 \mathrm{~d}$. (h) Seawater with w/c of 0.48 cured for $7 \mathrm{~d}$. 
However, when the w/c ratio was increased to 0.48 (Figures $7(\mathrm{c})$ and $7(\mathrm{~d})$ ), it is hard to find ettringite on the SEM figures of CSA cement cured for $1 \mathrm{~d}$. After comparison of Figures 7(e) and 7(f), as well as 7(g) and 7(h), it is found that the density of CSA paste mixed with seawater is higher and the formation of ettringite is more uniform, which confirms that the contents in seawater can promote the hydration of cement and improve the microstructure of CSA cement.

Comparing Figures $7(\mathrm{a})$ and $7(\mathrm{c})$, as well as $7(\mathrm{~b})$ and $7(\mathrm{~d})$, it can be found that the difference between the samples with w/c ratio of 0.40 and 0.48 after $1 \mathrm{~d}$ hydration is not particularly obvious, but the matrix of the sample with a greater w/c ratio is looser and the ettringite is less on the whole. From the comparison of Figures 7(e) and 7(g), as well as $7(\mathrm{f})$ and $7(\mathrm{~h})$, it can be seen that the difference of samples with different w/c ratios is more evident after curing for $7 \mathrm{~d}$. The compactness of the CSA cement matrix with a $\mathrm{w} / \mathrm{c}$ ratio of 0.40 is higher, and the matrix with a w/c ratio of 0.48 is more porous. The main reason is that seawater can provide more free $\mathrm{SO}_{4}^{2-}$ for CSA paste to hydrate. The increase of sulfate ions can increase the formation of ettringite, which helps to improve the compactness of CSA cement.

Although the hydration of CSA cement with a w/c ratio of 0.48 is more complete, the higher $\mathrm{w} / \mathrm{c}$ ratio provides more free water, which creates more capillary pores during hydration and evaporation. Therefore, the microstructure of CSA cement with a higher w/c ratio is looser and more porous.

\section{Conclusions}

In this research, an experimental investigation on the influence of the $\mathrm{w} / \mathrm{c}$ ratio and the types of mixing water on the early hydration of CSA cement via setting time, physical properties, compressive strength, chemical shrinkage, SEM, and XRD was carried out. Based on the experimental study, the following conclusions can be made:

(1) The hydration rate of CSA cement is very fast, and most of the hydration reactions are completed after curing for $3 \mathrm{~d}$.

(2) The w/c ratio has a significant effect on the performance of CSA cement. The increase of w/c ratio can speed up the hydration reaction, delay the setting time, decrease the strength, increase the chemical shrinkage, and make the cement matrix looser and more porous.

(3) Seawater can promote the hydration of CSA cement, delay the setting time, and increase the compactness of the CSA paste matrix.

(4) Seawater can rapidly promote the formation of ettringite in CSA cement after curing for $1 \mathrm{~h}$, which can improve the early strength of CSA cement. However, the rapidly generated ettringite causes the expansion of the CSA cement matrix and produces microcracks in the interior, which reduces the compressive strength, resulting in lower strength in the later stage of hydration compared to that of CSA cement mixed with freshwater.

\section{Data Availability}

The experimental results data used to support the findings of this study are included within the article.

\section{Conflicts of Interest}

The authors declare that they have no conflicts of interest.

\section{Acknowledgments}

This work was financially supported by the Key Laboratory of Structure and Wind Tunnel of Guangdong Higher Education Institutes Open Fund (202002), Basic Research Program of Natural Science in Shaanxi Province (2021JQ605), and Shantou University Research Start-up Fund (NTF17011).

\section{References}

[1] J. Chang, K. Cui, and Y. Zhang, "Effect of hybrid steel fibers on the mechanical performances and microstructure of sulphoaluminate cement-based reactive powder concrete," Construction and Building Materials, vol. 261, Article ID $120502,2020$.

[2] G. Li, J. Zhang, Z. Song, C. Shi, and A. Zhang, "Improvement of workability and early strength of calcium sulphoaluminate cement at various temperature by chemical admixtures," Construction and Building Materials, vol. 160, pp. 427-439, 2018.

[3] S. Fei, Y. Zhenglei, F. Yang, Y. Liu, and Y. Lu, "Strätlingite and calcium hemicarboaluminate hydrate in belite-calcium sulphoaluminate cement," Ceramics-Silikáty.vol. 58, no. 4, pp. 269-274, 2014.

[4] X. Guo, H. Shi, W. Hu, and K. Wu, "Durability and microstructure of csa cement-based materials from mswi fly ash," Cement and Concrete Composites, vol. 46, pp. 26-31, 2014.

[5] L. Lu, Z. Lu, S. Liu, S. Wang, and X. Cheng, "Durability of alite-calcium barium sulphoaluminate cement," Journal of Wuhan University of Technology, vol. 24, no. 6, pp. 982-985, 2009.

[6] Y. Wang, M. Su, and L. Zhang, Sulphoaluminate Cement, Beijing University of Technology Press, Beijing China, 1999.

[7] J. Zhang, G. Ke, and Y. Liu, "Experimental study on shrinkage reduction of calcium sulphoaluminate cement concrete with addition of pre-wetted lightweight aggregate," Construction and Building Materials, vol. 253, Article ID 119149, 2020.

[8] M. S. Imbabi, C. Carrigan, and S. McKenna, "Trends and developments in green cement and concrete technology," International Journal of Sustainable Built Environment, vol. 1, no. 2, pp. 194-216, 2012.

[9] M. L. Pace, A. Telesca, M. Marroccoli, and G. L. Valenti, "Use of industrial byproducts as alumina sources for the synthesis of calcium sulfoaluminate cements," Environmental Science \& Technology, vol. 45, no. 14, pp. 6124-6128, 2011.

[10] W. Hou, Z. Liu, F. He, J. Huang, and J. Zhou, "Sulfate diffusion in calcium sulphoaluminate mortar," Construction and Building Materials, vol. 234, Article ID 117312, 2020. 
[11] R. Ragoug, O. O. Barberon, J.-M. Torrenti et al., "Durability of cement pastes exposed to external sulfate attack and leaching: physical and chemical aspects," Cement and Concrete Research, vol. 116, pp. 134-145, 2019.

[12] Q. Xu, T. Ji, Z. Yang, and Y. Ye, "Steel rebar corrosion in artificial reef concrete with sulphoaluminate cement, sea water and marine sand," Construction and Building Materials, vol. 227, Article ID 116685, 2019.

[13] F. Bertola, D. Gastaldi, S. Irico, G. Paul, and F. Canonico, "Behavior of blends of csa and portland cements in high chloride environment," Construction and Building Materials, vol. 262, Article ID 120852, 2020.

[14] C. W. Hargis, B. Lothenbach, C. J. Müller, and F. Winnefeld, "Carbonation of calcium sulfoaluminate mortars," Cement and Concrete Composites, vol. 80, pp. 123-134, 2017.

[15] F. Winnefeld and B. Lothenbach, "Hydration of calcium sulfoaluminate cements - experimental findings and thermodynamic modelling," Cement and Concrete Research, vol. 40, no. 8, pp. 1239-1247, 2010.

[16] H. S. Wong and N. R. Buenfeld, "Determining the watercement ratio, cement content, water content and degree of hydration of hardened cement paste: method development and validation on paste samples," Cement and Concrete Research, vol. 39, no. 10, pp. 957-965, 2009.

[17] S. B. Singh, P. Munjal, and N. Thammishetti, "Role of water/ cement ratio on strength development of cement mortar," Journal of Building Engineering, vol. 4, pp. 94-100, 2015.

[18] J. Wang, J. Xie, Y. Wang, Y. Liu, and Y. Ding, "Rheological properties, compressive strength, hydration products and microstructure of seawater-mixed cement pastes," Cement and Concrete Composites, vol. 114, Article ID 103770, 2020.

[19] M. Luo, Q. Zeng, X. Pang, and K. Li, "Effect of curing conditions on pore structure of cement based materials," Journal of the Chinese Ceramic Society.vol. 41, no. 5, pp. 597-604, 2013.

[20] J.-k. Zhou and L.-m. Ge, "Effect of strain rate and water-tocement ratio on compressive mechanical behavior of cement mortar," Journal of Central South University, vol. 22, no. 3, pp. 1087-1095, 2015.

[21] V. Zivica, "Effects of the very low water/cement ratio," Construction and Building Materials, vol. 23, no. 12, pp. 3579-3582, 2009.

[22] H. Shi, Q. Wu, Z. Yu, J. Ma, and X. Shen, "Properties of ecofriendly coral sand powder - calcium sulfoaluminate cement binary system," Construction and Building Materials, vol. 263, Article ID 120181, 2020.

[23] B. Lu and Y. Liang, "Experimental study of concrete prepared with coral reef and sea water I," Bulletin of Marine Science.vol. 5, pp. 69-74, 1993.

[24] J. Wang, E. Liu, and L. Li, "Multiscale investigations on hydration mechanisms in seawater opc paste," Construction and Building Materials, vol. 191, pp. 891-903, 2018.

[25] T. Nishida, N. Otsuki, H. Ohara, Z. Garba-Say, and M. T. Nagata, "Some considerations for the applicability of seawater as mixing water in concrete," Journal of Materials in Civil Engineering, vol. 27, no. 7, Article ID 4014004, 2013.

[26] T. U. Mohammed, H. Hamada, and T. Yamaji, "Performance of seawater-mixed concrete in the tidal environment," Cement and Concrete Research, vol. 34, no. 4, pp. 593-601, 2004.

[27] A. Neville, "Seawater in the mixture," Concrete International, vol. 23, no. 1, pp. 48-51, 2001.

[28] M. Islam, S. Islam, M. Islam, and A. Amin, "Suitability of sea water on curing and compressive strength of structural concrete," Journal of Civil Engineering (IEB), vol. 40, no. 1, pp. 37-45, 2012.

[29] S. K. Kaushik and S. Islam, "Suitability of sea water for mixing structural concrete exposed to a marine environment," $\mathrm{Ce}$ ment and Concrete Composites, vol. 17, no. 3, pp. 177-185, 1995.

[30] J. Xiao, C. Qiang, A. Nanni, and K. Zhang, "Use of sea-sand and seawater in concrete construction: current status and future opportunities," Construction and Building Materials, vol. 155, pp. 1101-1111, 2017.

[31] Z. Shi, Z. Shui, Q. Li, and H. Geng, "Combined effect of metakaolin and sea water on performance and microstructures of concrete," Construction and Building Materials, vol. 74, pp. 57-64, 2015.

[32] W. Liu, H. Cui, Z. Dong, F. Xing, H. Zhang, and T. Y. Lo, "Carbonation of concrete made with dredged marine sand and its effect on chloride binding," Construction and Building Materials, vol. 120, pp. 1-9, 2016.

[33] C. X. Xu, Z. W. Ou, J. L. Zhou, H. B. Chen, and Q. Chen, "Investigation on protectional ability on steel bar of compound corrosion inhibitor applied in seawater-and-sea sand concrete," Applied Mechanics and Materials, vol. 71-78, pp. 864-870, 2011.

[34] A. Telesca, M. Marroccoli, M. L. Pace, M. Tomasulo, G. L. Valenti, and P. J. M. Monteiro, "A hydration study of various calcium sulfoaluminate cements," Cement and Concrete Composites, vol. 53, pp. 224-232, 2014.

[35] S. Ma, X. Shen, Y. Huang, and B. Zhong, "Preparation and formation mechanism of calcium sulphoaluminate," Journal of the Chinese Ceramic Society, vol. 36, no. 1, pp. 78-81, 2008.

[36] GB/T 1346-2011, Test Methods for Water Requirement of Normal Consistency, Setting Time and Soundness of the Portland Cement, Standardization Administration of China, Beijing, China, 2017.

[37] ASTM C1602-12, Standard Test Method for Chemical Shrinkage of Hydraulic Cement Paste, ASTM International, West Conshohocken, PA, USA, 2007.

[38] ASTM C20-2015, Standard Test Method for Apparent Porosity, Water Absorption, Apparent Specific Gravity, and Bulk Density of Burned Refractory Brick and Shapes by Boling Water, ASTM International, West Conshohocken, PA, USA, 2015.

[39] A. Younis, U. Ebead, P. Suraneni, and A. Nanni, "Fresh and hardened properties of seawater-mixed concrete," Construction and Building Materials, vol. 190, pp. 276-286, 2018.

[40] C. Yu, Q. Wu, and J. Yang, "Effect of seawater for mixing on properties of potassium magnesium phosphate cement paste," Construction and Building Materials, vol. 155, pp. 217-227, 2017.

[41] Q. Huang, Y. Li, W. Zheng, J. Wen et al., "Investigation on the properties of magnesium oxychloride cement prepared with seawater," Advances in Cement Research, vol. 32, no. 8, 2019. 